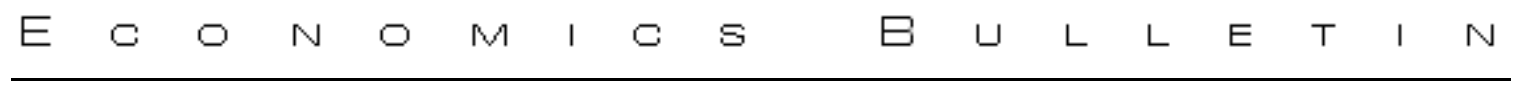

\title{
Inflation shocks and interest rate rules
}

\author{
Barbara Annicchiarico \\ Department of Economics, University of Rome 'Tor \\ Vergata"
}

\author{
Alessandro Piergallini \\ Centre for Financial Management Studies (CeFiMS), \\ SOAS, University of London
}

\begin{abstract}
Recent empirical evidence by Fair $(2002,2005)$ and Giordani (2003) shows that a positive inflation shock with the nominal interest rate held constant has contractionary effects. These results cannot be reconciled with the standard 'New Synthesis' literature. This paper reconsiders the effects of inflation shocks in a simple New Keynesian framework extended to include wealth effects. It is shown that, following an inflation shock, the decline of output coupled with passive interest rate rules is not puzzling.
\end{abstract}

We are very grateful to Jean-Pascal Bénassy for his helpful comments and suggestions on a earlier version of this paper. Thanks are also due to Andrea Costa, Jordi Galí, Nicola Giammarioli, and Giancarlo Marini for useful comments and discussions. Financial support from CNR and the FIRB project is gratefully acknowledged. The usual disclaimer applies. A detailed Technical Appendix to the paper is available from the authors upon request.

Citation: Annicchiarico, Barbara and Alessandro Piergallini, (2006) "Inflation shocks and interest rate rules." Economics Bulletin, Vol. 5, No. 19 pp. 1-7

Submitted: August 25, 2006. Accepted: December 12, 2006.

URL: http://economicsbulletin.vanderbilt.edu/2006/volume5/EB-06E50009A.pdf 


\section{Introduction}

The response of the economy to inflation shocks has received considerable attention in the literature. Recent empirical contributions by Fair (2002, 2005) and Giordani (2005) show that positive inflation shocks have contractionary effects on output even when the nominal interest rate is not increased. ${ }^{1}$ These results cast doubts on the validity of the predictions of dynamic New Keynesian models, where increases in inflation require a monetary policy responding with a more than one-to-one increase in the nominal interest rate (the so-called 'Taylor principle'), in order to guarantee macroeconomic stability and equilibrium uniqueness.

The present paper attempts to reconcile this recent empirical evidence with the New Keynesian literature. The standard 'New Synthesis' approach is based on the representative agent framework with infinite-horizon consumers (e.g., McCallum and Nelson, 1999; Taylor, 1999; Clarida et al., 1999; Galí, 2003; Woodford, 2003), thereby ignoring redistributions of wealth across generations. The IS relation is derived from the log-linearization of the standard Euler equation characterizing the household's optimal trade-off between current consumption and saving. Hence, monetary policy decisions are transmitted to the economy only through their effects on real interest rates. When fiscal solvency is ensured, equilibrium indeterminacy is ruled out if and only if the Taylor principle applies. This requirement ensures that the real interest rate will be moved upward when inflation exceeds its target, thereby producing contractionary effects on aggregate demand. By contrast, 'passive' interest rate rules, underreacting to inflation pressures, are destabilizing and give rise to sunspot fluctuations.

In this paper, we relax the assumption of the immortal representative agent by introducing overlapping generations (OLG) à la Yaari (1965) and Blanchard (1985) into a stochastic framework with monopolistic competition and staggered price adjustment. There are strong reasons for using an OLG setup. The framework employed maintains the main features of the so called 'New Synthesis' and encompasses the standard representative agent paradigm as a special case. Differently from the standard general equilibrium framework with a single infinitely lived consumer, OLG models are shown to be capable of generating "liquidity effects" (see Bénassy, 2006), thereby capturing a well established empirical feature of the monetary policy transmission mechanism (e.g., Christiano et al., 1997). As demonstrated by Bénassy (2006), liquidity effects are produced by intergenerational wealth effects. For the latter to be operative in a dynamic optimizing model, it is necessary and sufficient to have a positive birth rate (see Weil, 1989).

Most importantly for our purposes, consistently with the original findings by Bénassy (2000, 2005), passive interest rate rules, including pure interest rate pegs, do not cause sunspots and equilibrium multiplicities, being compatible with the existence of a determinate rational-expectations equilibrium. This property of the OLG setup enables us to study the effects of inflation shocks under both 'active' and 'passive' monetary policies.

Positive inflation shocks produce a redistribution of real wealth from current to future generations. Under these circumstances, the nominal interest rate must not necessarily be forced to increase more than proportionally with inflation to produce contractionary effects on current aggregate demand and guarantee stability. We show that an inflation shock has negative effects on the time path of output and consequently of inflation even under a 'passive' monetary policy rule. Our results thus provide sound micro-foundations to the empirical findings by Fair $(2002,2005)$ and Giordani (2003).

\footnotetext{
${ }^{1}$ Fair obtains his results in structural econometric models, while Giordani uses a VAR analysis.
} 
The scheme of the paper is as follows. Section 2 presents a baseline dynamic New Keynesian model extended to incorporate OLG. The analysis of equilibrium dynamics under interest rate feedback rules à la Taylor is developed in Section 3. Section 4 concludes.

\section{The Model}

\subsection{Consumers}

The demand-side of the economy is described by an extended stochastic discrete-time version of the Yaari (1965)-Blanchard (1985) perpetual youth model, where labor supply decisions are explicitly included. To keep the analysis as simple as possible, we assume a 'cashless' economy, according to the standard literature (e.g. Woodford, 2003). ${ }^{2}$ Private agents have identical preferences and face the same constant probability of death, $\gamma \in$ $(0,1)$, in each period of time. Population is assumed to be constant over time and the total size is normalized to one. Individuals are indexed by $j \in[0,1]$. At each date a new generation of size $\gamma$ is born and a fraction of equal size of the population passes away. Since there is no bequest motive and lifetime is uncertain, a life insurance market is assumed to be operative, as in Yaari (1965) and Blanchard (1985): competitive insurance companies collect financial wealth from the deceased members of the population and pay fair premia to survivors. The zero profit condition in the insurance sector implies that the gross return on the insurance contract, incorporated in the individual flow budget constraint, is $1 /(1-\gamma)$.

The representative agent $j$ of the generation born at time $s \leq 0$ maximizes the following expected lifetime utility function:

$$
E_{0} \sum_{t=0}^{\infty}[\beta(1-\gamma)]^{t} U\left(C_{s, t}(j), N_{s, t}(j)\right),
$$

where $\beta \in(0,1)$ is the subjective discount factor, $C_{s, t}(j)$ is consumption of the final good, and $N_{s, t}(j)$ denotes agent's labor, that is assumed to be supplied under monopolistic competition. ${ }^{3}$ In particular, each agent $j$ faces a demand function for her labor services given by $N_{s, t}(j)=\left(W_{s, t}(j) / W_{t}\right)^{-\eta_{t}} N_{t}$, where $N_{t}$ denotes total employment, $\eta_{t}>1$ is the elasticity of substitution between differentiated labor inputs, allowed to change over time, $W_{s, t}(j)$ is the individual nominal wage rate, and $W_{t}=\left(\int_{0}^{1} W_{t}(j)^{1-\eta_{t}} d j\right)^{1 /\left(1-\eta_{t}\right)}$ is the aggregate wage index. The flow budget constraint of the representative agent born at time $s$ is

$$
\frac{B_{s, t+1}(j)}{R_{t}} \leq \frac{1}{1-\gamma}\left(B_{s, t}(j)+W_{s, t}(j) N_{s, t}(j)+Z_{s, t}(j)-T_{s, t}(j)-P_{t} C_{s, t}(j)\right),
$$

where $P_{t}$ is the price of the final good, $B_{s, t}(j)$ denote nominal riskless government bonds carried over from period $t-1$ and paying one unit of numéraire in period $t, R_{t}$ denotes the gross nominal interest rate on bonds purchased in period $t, Z_{s, t}(j)$ is the share in the profits of intermediate goods firms, $T_{s, t}(j)$ denote nominal lump-sum net taxes. For

\footnotetext{
${ }^{2}$ The role of monetary aggregates in a dynamic stochastic New Keynesian model with OLG is discussed in Piergallini (2006).

${ }^{3}$ This feature of the model provides an analytically tractable way to introduce a 'cost-push' shock on inflation (e.g., Clarida et al., 2002).
} 
analytical convenience, profit shares and lump-sum net taxes are age-independent and newly born agents do not hold any financial assets.

To obtain a tractable solution, we focus on the following period utility function: ${ }^{4}$

$$
U\left(C_{s, t}(j), N_{s, t}(j)\right) \equiv \log \left[C_{s, t}(j)-V\left(N_{s, t}(j)\right)\right],
$$

where the function $V(\bullet)$ is such that $V^{\prime}(\bullet), V^{\prime \prime}(\bullet)>0$. Solving the individual maximizing problem and aggregating over all generations alive, where the aggregate value $X_{t}$ of a generic economic variable $X_{s, t}$ is defined as $X_{t} \equiv \sum_{s=-\infty}^{t}\left(\int_{0}^{\gamma(1-\gamma)^{t-s}} X_{s, t}(j) d j\right)$, yield:

$$
\begin{aligned}
& \frac{B_{t+1}}{R_{t}}=B_{t}+W_{t} N_{t}+Z_{t}-T_{t}-P_{t} C_{t}, \\
& P_{t} \Omega_{t}=\Psi\left[B_{t}+H_{t}-E_{t} \sum_{T=t}^{\infty} Q_{t, T}(1-\gamma)^{T-t} P_{T} V\left(N_{T}\right)\right] \text {, } \\
& \frac{W_{t}}{P_{t}}=\left(1+u_{t}^{w}\right) V^{\prime}\left(N_{t}\right),
\end{aligned}
$$

where $\Psi \equiv[1-\beta(1-\gamma)], Q_{t, T}$ is the relevant stochastic discount factor, $\Omega_{t} \equiv\left[C_{t}-V\left(N_{t}\right)\right]$ is aggregate consumption net of its subsistence level (see Ascari and Rankin, 2006), $H_{t} \equiv E_{t} \sum_{T=t}^{\infty} Q_{t, T}(1-\gamma)^{T-t}\left(W_{T} N_{T}+Z_{T}-T_{T}\right)$ is aggregate human wealth, and $u_{t}^{w}=$ $1 /\left(\eta_{t}-1\right)$ is the exogenous optimal wage mark-up. Given equations (4) and (5) and using the definition of human wealth, one can derive the dynamic equation of 'adjusted' consumption as

$$
P_{t} \Omega_{t}=\frac{1}{\beta} E_{t}\left\{Q_{t, t+1} P_{t+1} \Omega_{t+1}\right\}+\frac{\gamma \Psi}{\beta(1-\gamma)} E_{t}\left\{Q_{t, t+1} B_{t+1}\right\}
$$

The time path of adjusted consumption is affected by the level of financial wealth.

\section{$2.2 \quad$ Firms}

The supply-side of the economy is described by a continuum of monopolistic firms, indexed by $i$, each producing a variety $i$ of the differentiated intermediate goods and setting prices in a staggered fashion. All intermediate goods are employed as inputs by perfectly competitive firms producing the single final good.

The final good representative firm faces a CES technology, $Y_{t}=\left(\int_{0}^{1} \Xi_{t}(i)^{(\varepsilon-1) / \varepsilon} d i\right)^{\varepsilon /(\varepsilon-1)}$, where $Y_{t}$ denotes aggregate output and $\Xi_{t}(i)$ is the quantity of intermediate good produced by firm $i$. Profit maximization yields the demand for each intermediate good $i$ as a function of the relative price of $i$ and of total production, $\Xi_{t}(i)=\left(P_{t}(i) / P_{t}\right)^{-\varepsilon} Y_{t}$. In addition, the zero profit condition implies $P_{t}=\left(\int_{0}^{1} P_{t}(i)^{1-\varepsilon} d i\right)^{1 /(1-\varepsilon)}$.

Each intermediate good producer faces a linear production function, $Y_{t}(i)=N_{t}(i)$, where $N_{t}(i)=\left(\int_{0}^{1} N_{t}(i, j)^{\left(\eta_{t}-1\right) / \eta_{t}} d j\right)^{\eta_{t} /\left(\eta_{t}-1\right)}$ represents labor services used by firm $i .^{5}$

\footnotetext{
${ }^{4}$ Ascari and Rankin (2006) provide strong reasons to prefer this family of utility functions in OLG models with endogenous labor supply. They show that the present preferences' specification removes a negative labor supply problem which may arise for older generations in models à la Yaari-Blanchard with leisure in the utility function when leisure is a normal good.

${ }^{5}$ For simplicity, we have normalized the level of labor productivity to one.
} 
The nominal marginal cost, $M C_{t}^{n}$, is given by the wage rate $W_{t}$ and thus is identical across firms. Following Calvo (1983), each period a firm keeps its price fixed with probability $\theta$. Hence $P_{t}=\left[\sum_{s=-\infty}^{t}(1-\theta) \theta^{t-s} \Lambda_{s}^{1-\varepsilon}\right]^{1 /(1-\varepsilon)}$, where $\Lambda_{s}$ denotes the price set by firms able to revise their pricing decisions in period $s$. At the optimum $\Lambda_{t}$ is equal to a mark-up over a weighted average of expected future nominal marginal cost:

$$
E_{t} \sum_{T=t}^{\infty} \theta^{T-t} Q_{t, T} Y_{T} P_{T}^{\varepsilon}\left[\Lambda_{t}-\left(1+u^{p}\right) M C_{T}^{n}\right]=0,
$$

where $u^{p}=1 /(\varepsilon-1)$ is the net mark-up. At the symmetric equilibrium the price index follows a law of motion given by $P_{t}=\left[\theta P_{t-1}^{1-\varepsilon}+(1-\theta) \Lambda_{t}^{1-\varepsilon}\right]^{1 / 1-\varepsilon}$.

\subsection{The Public Sector}

The government issues nominal debt in the form of interest-bearing bonds $B_{t}$. For the sake of simplicity and without loss of generality, we set the level of public expenditure to zero. Thus, the flow budget constraint of the government in nominal terms is given by

$$
\frac{B_{t+1}}{R_{t}}=B_{t}-T_{t}
$$

The solvency condition requires that $\lim _{T \rightarrow \infty} E_{t}\left\{Q_{t, T} B_{T}\right\}=0$. We focus on a fiscal policy regime which allows for non-zero secondary surpluses or deficits of the kind prescribed by the budget rules of the Stability and Growth Pact in the European Monetary Union. In particular, we follow Schmitt-Grohé and Uribe (2000) and consider a budget rule where the sequence of secondary surpluses, $\left\{S_{t}\right\}_{t=0}^{\infty}$, is exogenous and bounded. Hence, lump-sum net taxes are given by

$$
T_{t}=\left(R_{t-1}-1\right) \frac{B_{t}}{R_{t-1}}+S_{t}
$$

Substituting (10) into the government's flow budget constraint (9) yields the following expression for the evolution of outstanding public debt:

$$
\frac{B_{t+1}}{R_{t}}=\frac{B_{t}}{R_{t-1}}-S_{t}=D_{t}^{n}
$$

where $D_{t}^{n} \equiv B_{0} / R_{-1}-\sum_{T=0}^{t} S_{T}$.

The monetary authorities adopt an interest rate feedback rule of Taylor's type, where the nominal interest rate is set as an increasing function of the inflation rate:

$$
R_{t}=R\left(\frac{P_{t}}{P_{t-1}}\right)^{\phi_{\pi}}
$$

where $\phi_{\pi}$ is a non-negative parameter and $R$ is the steady state gross nominal interest rate equal to the real rate in a zero-inflation steady state.

\subsection{Equilibrium}

Equilibrium in the goods market requires $Y_{t}(i)=\Xi_{t}(i)$, for all $i \in[0,1]$, and $Y_{t}=C_{t}$. Equilibrium in the labor market implies $N_{t}=\int_{0}^{1} N_{t}(i) d i=Y_{t} \int_{0}^{1}\left(Y_{t}(i) / Y_{t}\right) d i$. Hence, the aggregate production function is $Y_{t}=N_{t} / \delta_{t}$, where $\delta_{t} \equiv \int_{0}^{1}\left(P_{t}(i) / P_{t}\right)^{-\varepsilon} d i$ represents a dispersion index of relative prices across firms. 


\section{Inflation Shocks and Equilibrium Dynamics}

To investigate equilibrium dynamics under inflation shocks, we perform a first-order loglinear approximation of the global system around a non-stochastic steady state with zero inflation and positive public debt. Letting $x_{t}$ be the log-deviation of a generic variable $X_{t}$ from its steady state value $X$, equilibrium dynamics can be shown to be described by the following Is equation and Phillips curve:

$$
\begin{gathered}
y_{t}=-\frac{1}{\sigma(1+\lambda)}\left(r_{t}-E_{t}\left\{\pi_{t+1}\right\}\right)+\frac{1}{1+\lambda} E_{t}\left\{y_{t+1}\right\}+\frac{\lambda}{\sigma(1+\lambda)} d_{t}, \\
\pi_{t}=\frac{1}{R} E_{t}\left\{\pi_{t+1}\right\}+\kappa y_{t}+u_{t},
\end{gathered}
$$

where $\lambda \equiv \gamma \Psi R D^{n} /(1-\gamma) P \Omega, \sigma \equiv\left[1-V^{\prime}(Y)\right] Y / \Omega=Y / \varepsilon \Omega, \kappa \equiv \varepsilon V^{\prime \prime}(Y) Y(1-\theta) \times$ $(R-\theta) /[R \theta(\varepsilon-1)], \pi_{t} \equiv p_{t}-p_{t-1}$ is the inflation rate, $d_{t} \equiv\left(d_{t}^{n}-p_{t}\right)$ is the endof-period real public debt, and $u_{t} \equiv[(1-\theta)(R-\theta) / R \theta] u_{t}^{w}$ is the source of inflation shocks, assumed to obey a first-order autoregressive process, $u_{t}=\rho_{u} u_{t-1}+\varepsilon_{t}^{u}$, being $\left\{\varepsilon_{t}^{u}\right\}$ a white noise and $\rho_{u} \in[0,1)$. In the present optimizing framework with OLG the current level of financial liabilities of the government is net wealth for the living generations. Changes in the level of public debt in real terms tend to change the current level of aggregate output into the same direction. It should be noted that in the limiting case of the infinitely-lived representative agent setup, where $\lambda=0$, intergenerational wealth effects are not operative and equation (13) collapses into the standard New Keynesian IS equation. The end-of-period real public debt by definition evolves as follows:

$$
d_{t}=d_{t-1}-\pi_{t}+\Delta d_{t}^{n}
$$

where the term $\Delta d_{t}^{n}$ can be interpreted as a secondary deficit disturbance, assumed to be exogenous and bounded.

The structural equations (13) and (14) determine $y_{t}$ and $\pi_{t}$ conditional on the time paths of both the real public debt, $d_{t}$, and the nominal interest rate, $r_{t}$. The latter is implied by the log-linear version of the monetary policy rule (12):

$$
r_{t}=\phi_{\pi} \pi_{t}
$$

Monetary policy is 'active' ('passive') if and only if $\phi_{\pi}>(<) 1$.

To study the dynamic properties of the model, we use the following definitions.

Definition 1. A rational-expectations equilibrium is a set of sequences $\left\{y_{t}, \pi_{t}, d_{t}, r_{t}\right\}_{t=0}^{\infty}$ satisfying (13), (14), (15) and (16) for a given set of exogenous bounded processes $\left\{\Delta d_{t}^{n}, u_{t}\right\}_{t=0}^{\infty}$ and an initial value of financial wealth $d_{-1}$.

DeFInITION 2. The model exhibits a determinate rational-expectations equilibrium if the system composed of (13), (14), (15) and (16) has a unique bounded solution for $\left\{y_{t}, \pi_{t}, d_{t}, r_{t}\right\}_{t=0}^{\infty}$, given the initial condition $d_{-1}$ and the bounded disturbance processes $\left\{\Delta d_{t}^{n}, u_{t}\right\}_{t=0}^{\infty}$.

We can now state the following proposition.

Proposition 1. The interest rate rule (16) implies a determinate rational-expectations equilibrium for each value of the monetary policy response coefficient $\phi_{\pi} \geq 0$.

Proof: The system (13), (14), (15) and (16) can be written in matrix form as 


$$
E_{t}\left\{\mathbf{x}_{t+1}\right\}=\mathbf{M} \mathbf{x}_{t}+\mathbf{Q} \mathbf{e}_{t}
$$

where the vector of endogenous variables is $\mathbf{x}_{t}=\left[\begin{array}{lll}\pi_{t} & y_{t} & d_{t-1}\end{array}\right]^{\prime}$, the vector of exogenous variables is $\mathbf{e}_{t}=\left[\begin{array}{ll}\Delta d_{t}^{n} & u_{t}\end{array}\right]^{\prime}$, and the matrices of coefficients are

$$
\mathbf{M}=\left[\begin{array}{ccc}
R & -R \kappa & 0 \\
\frac{1}{\sigma}\left(\phi_{\pi}+\lambda-R\right) & 1+\lambda+\frac{R \kappa}{\sigma} & -\frac{\lambda}{\sigma} \\
-1 & 0 & 1
\end{array}\right], \quad \mathbf{Q}=\left[\begin{array}{cc}
0 & -R \\
0 & 0 \\
1 & 0
\end{array}\right]
$$

The system (17) is composed of two non-predetermined variables, $\pi_{t}$ and $y_{t}$, and a predetermined one, $d_{t-1}$. Following Blanchard and Khan (1980), there exists a unique stable rational expectations solution if and only if matrix $\mathbf{M}$ has two eigenvalues outside the unit circle and one eigenvalue inside the unit circle. The characteristic equation of matrix $\mathbf{M}$ is of the form

$$
P(\mu)=\mu^{3}+M_{2} \mu^{2}+M_{1} \mu+M_{0}=0 .
$$

where $M_{0}=-\operatorname{det} \mathbf{M}=-\left[R(1+\lambda)+\frac{R \kappa \phi_{\pi}}{\sigma}\right]$ and

$$
\begin{aligned}
\left|M_{2}\right| & =\operatorname{tr} \mathbf{M}=2+R+\lambda+\frac{R \kappa}{\sigma}>3 \\
P(-1) & =-1+M_{2}-M_{1}+M_{0} \\
& =-\left[2(2+\lambda)(1+R)+\frac{R \kappa(2+\lambda+2 \phi)}{\sigma}\right]<0 \\
P(1) & =1+M_{2}+M_{1}+M_{0}=\frac{R \kappa \lambda}{\sigma}>0 .
\end{aligned}
$$

Conditions (19)-(21) are sufficient for equation (18) to have one root inside the unit circle and two roots outside. ${ }^{6}$

Consistently with the results first obtained by Bénassy (2000, 2005), the so-called 'Taylor principle', $\phi_{\pi}>1$, is not necessary to ensure equilibrium uniqueness. In a New Keynesian framework with non-Ricardian consumers, interest rate rules that underreact to inflation may well induce determinacy of equilibrium. An upward perturbation in inflation over its steady state value implies a lower level of real financial assets which tends to reduce consumption through the net wealth effect. Such a contractionary effect follows from the fact that inflation generates a redistribution of real wealth from current to future generations, because the reduction in the real value of government liabilities dampens the burden of future fiscal restrictions. Intergenerational wealth effects work as automatic stabilizers and make active interest rate rules unnecessary for equilibrium determinacy. This feature of our framework allows us to analyze the effects of inflation shocks under both 'active' and 'passive' interest rate rules.

To study the impact of inflation shocks for alternative values of the monetary policy coefficient on inflation, we parameterize the model assuming that each period corresponds to a quarter of year. We assume $V(N) \equiv N^{1+\varphi} /(1+\varphi)$, where $\varphi=V^{\prime \prime}(N) N / V^{\prime}(N)$ is the inverse of the Frisch elasticity. To make the argument as transparent as possible, we calibrate the model along the lines of the existing literature. We set the steady state public debt to GDP ratio at 0.6 at annual level, as in Benigno and Woodford (2003). The steady state real interest rate is 0.0125, as in McCallum (2001). The persistence

\footnotetext{
${ }^{6}$ See Woodford (2003).
} 
of the inflation shock is set equal to $\rho_{u}=0.3$. We calibrate the probability of death between two consecutive periods at $\gamma=0.015$. We set both the price mark-up $u^{p}$ and the inverse of the Frisch elasticity $\varphi$ equal to 0.2, consistently with Galí et al. (2006). The steady state fraction of time in employment is $1 / 3$, according to the standard eight hours working day. Finally, the probability of keeping the price fixed between two consecutive quarters is set at $\theta=0.66$, as in Rotemberg and Woodford (1997). Table 1 summarizes the parametrization of the model and reports the implied parameter values.

Figure 1 plots the responses of the economy to a positive inflation shock for different values of the monetary policy coefficient on inflation: $\phi_{\pi}=1.5$, as in the VolckerGreenspan era (Taylor, 1993), $\phi_{\pi}=0.85$, as in the pre-Volcker era in the U.S. (Taylor 1999), and $\phi_{\pi}=0$, i.e. the case of a pure interest rate peg.

For an inflation coefficient of $\phi_{\pi}=1.5$ the real interest rate and output move in opposite directions, consistently with the standard theory. However, a close inspection of impulse response functions reveals that even a monetary policy rule that responds to increases in inflation with a less than one-to-one increase in the nominal interest is stabilizing, contrary to the predictions of the standard New Keynesian models in which the equilibrium would be indeterminate. When the nominal interest rate is pegged at a constant level, $\phi_{\pi}=0$, following an inflation shock, both output and the real interest rate decline significantly on impact. At later stages inflationary shocks give rise to deflationary effects. For $\phi_{\pi}=0.85$, as in the pre-Volker era, we observe similar dynamic responses to a positive inflation shock, though, on impact, the contraction of output is larger while the real interest rate decline is less sharp.

The intuition behind our results is the following. After an inflation shock, real wealth of currently alive generations declines and output moves downwards. Inflation redistributes resources from current to future generations, since the decline in the real value of government liabilities reduces the tax load for yet unborn individuals. The presence of wealth effects in the IS equation does enhance the stability of the system, making the respect of the Taylor principle unnecessary in response to inflation shocks. When the Taylor principle is not satisfied following a positive inflation shock, the negative effects on output still come about because wealth effects tend to reduce aggregate demand redistributing resources from currently alive to future generations. However, the accommodating monetary policy decelerates the process of adjustment. In such circumstances, the more persistent negative effects on output generated by the initial shock bring about a deflationary adjustment path.

\section{Conclusions}

This paper has demonstrated how the explicit consideration of wealth effects in a baseline New Keynesian model can explain the decrease in output in response to an inflation shock in a way consistent with recent empirical evidence. Specifically, it has been shown that under passive monetary policies, inflationary shocks generate persistent and negative effects on aggregate demand giving rise to a deflationary adjustment path. An increase in inflation does not need to be counterbalanced by a more than proportional increase in the nominal interest rate to ensure economic stability.

In conclusion, the results derived in this paper suggest a possible simple solution to the seeming conflict between empirical evidence and the predictions of the existing New Keynesian literature regarding the effects of inflation shocks. 


\section{References}

Ascari, G., and N. Rankin (2006) "Perpetual Youth and Endogenous Labour Supply: A Problem and a Possible Solution" Journal of Macroeconomics, forthcoming.

Bénassy, J-P. (2000) "Price Level Determinacy under a Pure Interest Rate Peg", Review of Economic Dynamics 3, 194-211.

Bénassy, J-P. (2005) "Interest Rate Rules, Price Determinacy and the Value of Money in a Non-Ricardian World", Review of Economic Dynamics 8, 651-667.

Bénassy, J-P. (2006) "Liquidity Effects in Non-Ricardian Economies", Scandinavian Journal of Economics 108, 65-79.

Benigno, P., and M. Woodford (2003) "Optimal Targeting Rules for Monetary and Fiscal Policy" NBER Macroeconomics Annual Conference, April, 4-5, 2003.

Blanchard, O. J., and C. M. Kahn (1980) "The Solution of Linear Difference Models under Rational Expectations" Econometrica 48, 1305-1311.

Blanchard, O. J. (1985) "Debt, Deficits, and Finite Horizons" Journal of Political Economy 93, 223-247.

Calvo, G.A. (1983) "Staggered Prices in a Utility Maximizing Framework" Journal of Monetary Economics 12, 383-398.

Christiano, L.J., M. Eichenbaum, and C.L. Evans (1997) "Sticky Price and Limited Partecipation Models of Money: A Comparison" European Economic Review 41, 12011249 .

Clarida, R., J. Galí, and M. Gertler (1999) "The Science of Monetary Policy: A New Keynesian Perspective" Journal of Economic Literature 37, 1661-1707.

Clarida, R., J. Galí, and M. Gertler (2002) "A Simple Framework for International Monetary Policy Analysis" Journal of Monetary Economics 49, 879-904.

Fair, R.C. (2002) "On Modeling the Effects of Inflation Shocks" Contributions to Macroeconomics 2, art 3.

Fair, R.C. (2005) "Estimates of the Effectiveness of Monetary Policy" Journal of Money, Credit and Banking 37, 645-660.

Galí, J. (2003) "New Perspectives on Monetary Policy, Inflation, and the Business Cycle, in Advances in Economic Theory by M. Dewatripont, L. Hansen, and S. Turnovsky, Eds., Cambridge University Press: Cambridge, 151-197.

Galí, J., D. López-Salido, and J. Vallés (2006) "Understanding the Effects of Government Spending on Consumption" Journal of the European Economic Association, forthcoming.

Giordani, P. (2003) "On Modeling the Effects of Inflation Shocks: Comments and Some Further Evidence" Contributions to Macroeconomics 3, art. 1.

McCallum, B.T. (2001) "Monetary Policy Analysis in Models Without Money" Federal Reserve of St. Louis Review 83, 145-160.

McCallum, B.T., and E. Nelson (1999) "An Optimizing IS-LM Specification for Monetary Policy and Business Cycle Analysis" Journal of Money, Credit and Banking 31, 296-316.

Piergallini, A. (2006) "Real Balance Effects and Monetary Policy" Economic Inquiry 44, 497-511.

Rotemberg, J., and M. Woodford (1997) "An Optimizing-Based Econometric Framework for the Evaluation of Monetary Policy" in NBER Macroeconomic Annual by B. Bernanke and J. Rotemberg, Eds., The MIT Press: Cambridge MA, 297-346. 
Schmitt-Grohé, S., and M. Uribe (2000) "Price Level Determinacy and Monetary Policy under a Balanced-Budget Requirement" Journal of Monetary Economics 45, 211246.

Taylor, J.B. (1993) "Discretion Versus Policy Rules in Practice" Carnegie-Rochester Conference Series on Public Policy 39, 195-214.

Taylor, J. B. (1999) "A Historical Analysis of Monetary Policy Rules" in Monetary Policy Rules by J.B.Taylor, Ed., University of Chicago Press: Chicago and London, 319-347.

Weil, P. (1989) "Overlapping Families of Infinitely-Lived Agents" Journal of Public Economics 38, 183-198.

Woodford, M. (2003) Interest and Prices, Princeton University Press: Princeton and Oxford.

Yaari, M.E. (1965) "Uncertain Lifetime, Life Insurance, and the Theory of the Consumer" The Review of Economic Studies 32, 137-150. 
Table 1: Calibration

\begin{tabular}{lll}
\hline \hline Baseline Calibration & & \\
\hline Steady-state gross nominal (and real) interest rate & $R$ & 1.0125 \\
Steady-state public debt to GDP ratio & $\frac{D^{n}}{P Y}$ & 2.4 \\
Probability of death & $\gamma$ & 0.015 \\
Steady-state time in employment & $N$ & 0.33 \\
Price mark-up & $u^{p}$ & 0.2 \\
Inverse of the Frisch elasticity & $\varphi$ & 0.2 \\
Degree of price stickiness & $\theta$ & 0.66 \\
Persistence of inflation shock & $\rho_{u}$ & 0.3 \\
\hline \hline Implied Parameters & \multicolumn{3}{l}{} \\
\hline Discount factor & $\beta$ & 0.99 \\
Elasticity of substitution & $\varepsilon$ & 6 \\
IS parameter & $\sigma$ & 0.5 \\
Wealth effect parameter & $\lambda$ & 0.003 \\
Steady-state wage mark-up & \multicolumn{2}{l}{0.02} \\
Phillips curve parameter & $u^{w}$ & 0.02 \\
\hline
\end{tabular}



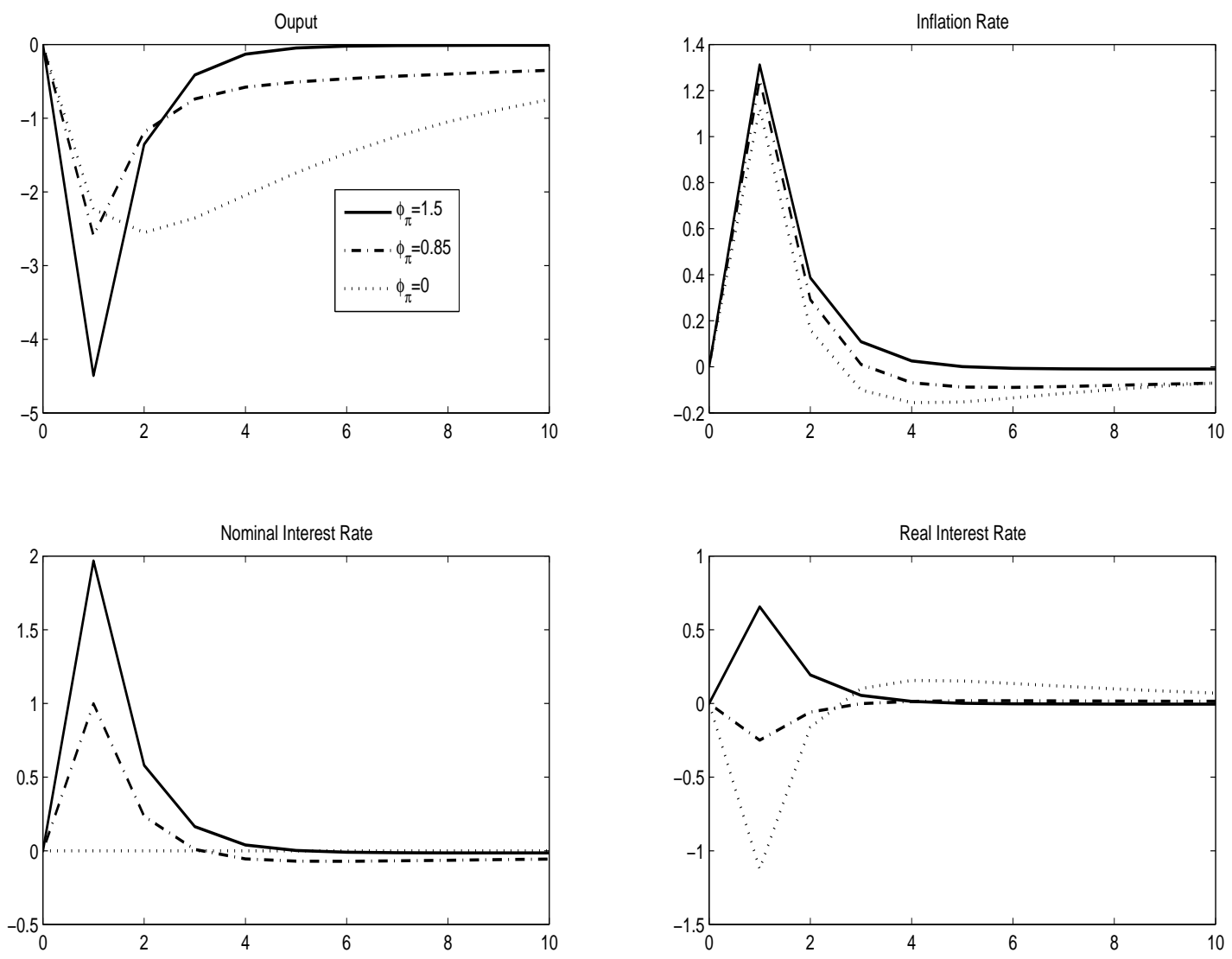

Figure 1: Dynamic Responses to a Unit Inflation Shock 